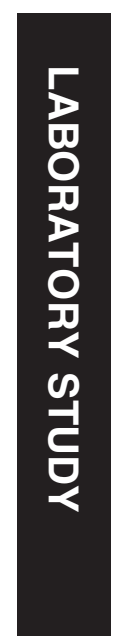

\section{Effects of intravitreal injection of bevacizumab on nitric oxide levels}

\begin{abstract}
Purpose This study aimed to determine the possible effects of single-dose intravitreal bevacizumab on nitric oxide (NO) levels in serum and remote organs and to reveal one of the possible mechanisms in the pathophysiology of hypertension. Methods Thirty-eight adult New Zealand albino rabbits were divided into a control group (no injection was performed, killed on day 28 of the study), group 1 (killed on day 1 of the study), group 2 (killed on day 7 of the study), group 3 (killed on day 14 of the study), and group 4 (killed on day 28 of the study). The right eyes of the animals in groups 1-4 received an intravitreal single injection of $1.25 \mathrm{mg}$ $(0.05 \mathrm{ml})$ bevacizumab (Avastin), and their brain, heart, liver, kidney, and blood samples were collected. NO levels were evaluated in the serum and organ homogenates. Kidney tissues were assessed by electron microscopy.

Results Serum, brain, kidney, and liver NO levels significantly decreased in groups 2, 3, and 4 as compared with the control group $(P<0.05)$. In addition, heart NO levels significantly decreased in groups 3 and 4 compared with the control group $(P<0.05)$. There were no electron microscopic changes in the kidneys of either group.

Conclusions This study demonstrated that single intravitreal injection of bevacizumab decreased NO levels in serum, brain, heart, liver, and kidneys. In addition, there were no electron microscopic changes in the kidneys. Eye (2015) 29, 436-442; doi:10.1038/eye.2014.297; published online 19 December 2014
\end{abstract}

\section{Introduction}

Vascular endothelial growth factor (VEGF) is a major inducer of angiogenesis, also inducing endothelial cell permeability, proliferation,
E Dinc ${ }^{1}$, O Yildirim¹, L Ayaz², T Ozcan ${ }^{3}$

and SN Yilmaz ${ }^{3}$ lymphogenesis, and vasodilation. ${ }^{1}$ VEGF-A is the most effective among VEGF isoforms on many physiological activities particularly on angiogenesis. VEGF signaling is mediated via two receptors: VEGFR1/Flt1 and VEGFR2 KDR/Flk1. 2,3 Stimulation of these receptors by VEGF is a key factor for pathologic angiogenesis and spread of various cancers. ${ }^{4}$ Antibodies and small molecules targeting VEGF have been developed to block the formation of tumor vessels and cause the regression of tumors. ${ }^{5}$

Bevacizumab (Avastin, Roche-Genentech Inc., South San Francisco, CA, USA) is a full-length, humanized monoclonal $\mathrm{IgG}_{1}$ antibody that binds to all isoforms of human VEGF. It was approved by the Food and Drug Administration in 2004 as the first anti-angiogenic agent and is used for the treatment of metastatic colorectal cancer. ${ }^{6}$ Bevacizumab has been used 'off-license' in many ocular diseases associated with neovascularization for the past years. Recently, several studies have reported the effects of intravitreal bevacizumab injections on reducing macular edema and retinal/choroidal neovascularization in patients with age-related macular degeneration (AMD), diabetic retinopathy, central vein occlusion, and degenerative myopia. ${ }^{7-11}$

The most common adverse effects of systemic bevacizumab include hypertension, proteinuria, hemorrhage, thromboembolic events, and gastrointestinal perforation. ${ }^{5}$ Michels et al ${ }^{12}$ reported a mild elevation of systolic blood pressure after systemic bevacizumab administration for neovascular AMD. They reported that the elevated blood pressure normalized 12 weeks after systemic administration. This study was then criticized by Rich et al, ${ }^{13}$ who claimed that blood pressure monitoring was performed by different examiners using different techniques. Thus, they postulated that the increase in systolic blood pressure was likely not clinically relevant 
with systemic bevacizumab administration.

Furthermore, it has been reported that use of single-dose intravitreal bevacizumab may increase systemic blood pressure or impair the control of blood pressure in hypertensive patients. ${ }^{14}$ It has been shown that acute infusions of VEGF cause vasodilation and hypotension, likely mediated by VEGFR2 and stimulation of nitric oxide (NO) synthesis and/or vasodilator prostanoids. ${ }^{15,16}$ Although the underlying mechanism of the development of hypertension induced by angiogenesis inhibition still remains to be elucidated, NO bioavailability is thought to be a critical factor.

In this study we aimed to determine the possible effects of single-dose intravitreal bevacizumab on NO levels in serum and remote organs and to reveal one of the possible mechanisms in the pathophysiology of hypertension.

\section{Materials and methods}

Approval for animal study was obtained from Mersin University Animal Studies Ethical Committee. All animals used in the study received human care in compliance with the guidelines established by the Committee, and all experiments were conducted in accordance with the Animal Care and Use Committee and the Association for Research in Vision and Ophthalmology (ARVO) statement for the Use of Animals in Ophthalmic and Vision Research. Full-length humanized monoclonal VEGF IgG antibody 'bevacizumab', which is commercially available (Avastin), was used in the study.

\section{Animals and experimental procedure}

Thirty-eight male, young adult, New Zealand albino rabbits weighing between 2.5 and $3.0 \mathrm{~kg}$ were used in this study. Rabbits were divided into a control group (no injection was performed, killed on day 28 of the study), group 1 (killed on day 1 of the study), group 2 (killed on day 7 of the study), group 3 (killed on day 14 of the study), and group 4 (killed on day 28 of the study). The right eyes of the animals in groups 1-4 received an intravitreal single injection of $1.25 \mathrm{mg}(0.05 \mathrm{ml})$ bevacizumab (Avastin), and their brain, heart, liver, kidney, and blood samples were collected. NO levels were evaluated in the serum and organ homogenates. Electron microscopy was used for the evaluation of pathological changes in the kidney tissues.

The rabbits were anesthetized with intramuscular injection of $50 \mathrm{mg} / \mathrm{kg}$ ketamine hydrochloride and $5 \mathrm{mg} / \mathrm{kg}$ xylazine hydrochloride. The right pupils were dilated with $0.5 \%$ tropicamide and $2.5 \%$ phenylephrine. After installation of topical $0.5 \%$ proparacaine, $5 \%$ povidone iodine was placed on the conjunctiva of the right eyes.

\section{Intravitreal injections}

Under sterile conditions the injections were performed $3.5 \mathrm{~mm}$ posterior to the limbus into the midvitreous cavity in the superonasal quadrant, by using a surgical microscope. The eyes of the rabbits were injected with $1.25 \mathrm{mg}(0.05 \mathrm{ml})$ bevacizumab (Avastin) using an insulin syringe with a 30 -gauge needle. The needle was carefully removed, and a sterile cotton applicator was used to prevent reflux. Topical moxifloxacin $0.5 \%$ eye drops were administered four times a day for a week after the procedure. All of the study eyes were clinically examined for corneal clarity, lens transparency, or any sign for inflammation or infection. At the end of the study, all rabbits were killed by intracardiac blood collection while still deeply anesthetized.

\section{Biochemical analysis}

Preparation of serum Serum samples were obtained from blood samples by centrifugation at $3000 \times g$ for $15 \mathrm{~min}$ at $4{ }^{\circ} \mathrm{C}$ and stored at $-80^{\circ} \mathrm{C}$ until $\mathrm{NO}$ levels were measured.

Preparation of tissue homogenates From each organ of the brain, heart, liver, and kidney, $50 \mathrm{mg}$ tissue samples were obtained. Then, tissue samples were homogenized in $1 \mathrm{ml}$ lysis buffer and centrifuged at $14000 \times \mathrm{g}$ for $15 \mathrm{~min}$ at $4{ }^{\circ} \mathrm{C}$. The cytosolic extracts were removed gently. NO was determined in the supernatants.

Determination of NO The levels of NO in the serum and tissue were analyzed by a colorimetric assay kit (nitric oxide colorimetric kit, Roche Diagnostics $\mathrm{GmbH}$, Mannheim, Germany). Nitrate is reduced to nitrite by reduced nicotinamide adenine dinucleotide phosphate in the presence of the enzyme nitrate reductase. The nitrite that was formed reacts with sulfanilamide and $\mathrm{N}$-(1naphtyl)-ethylene-diamine dihydrochloride to give a red-violet diazo dye. The diazo dye is measured on the basis of its absorbance in the visible range at $550 \mathrm{~nm}$. NO concentrations were given as $\mu \mathrm{mol} / \mathrm{l}$.

\section{Histological evaluation}

Electron microscopy Kidney samples for transmission electron microscopy were fixed in $2.5 \%$ glutaraldehyde for $4 \mathrm{~h}$. After fixation, specimens were rinsed in $0.1 \mathrm{M}$ phosphate buffer, $\mathrm{pH} 7.2$, post-fixed in $2 \% \mathrm{OsO}_{4}$ in $0.1 \mathrm{M}$ phosphate buffer for $2 \mathrm{~h}$, rinsed in distilled water, dehydrated in graded ethanol series, and embedded in 
epoxy resin. With a Leica UCT 125 ultramicrotome (Leica Microsystems $\mathrm{GmbH}$, Wien, Austria), $70 \mathrm{~nm}$ sections were obtained on 300 mesh cupper grids and stained with uranyl acetate and lead nitrate. The photographs were taken with a Megaview III digital camera (Olympus Soft Imaging Solutions $\mathrm{GmbH}$, Münster, Germany) and attached to a Jeol Jem-1011 (Jeol Ltd, Tokyo, Japan) transmission electron microscope.

\section{Statistical analysis}

Statistical analyses were performed with SPSS software package, version 17.0 for Windows (SPSS Inc., Chicago, IL, USA). NO results were controlled for normal distribution using the Shapiro-Wilk test and according to test results, all data were normally distributed. For NO data, statistical analysis was performed using repeated measurements of ANOVA followed by post hoc analysis with the Bonferroni test to detect differences between the groups. Results are expressed as mean \pm SD. A $P$-value of $<0.05$ was considered significant.

\section{Results}

\section{Clinical examination}

No corneal opacity, cataract, vitreous hemorrhage, or retinal detachment were observed. There were no signs of inflammation or infection in any of the eyes such as ciliary injection, inflammatory cells in the anterior chamber, or purulent secretion.

\section{Biochemical results}

Medication of rabbits with bevacizumab $(1.25 \mathrm{mg})$ at days 7,14 , and 28 caused a significant decrease in NO levels compared with the control group. There were no significant changes in serum NO levels in group 1 $(P=0.312)$ compared with the control group; however, in groups 2, 3, and 4, NO levels were decreased compared with the control group $(P=0.015, P=0.022$, and $P<0.0001$, respectively; Figure 1). Brain NO levels in group $1(P=0.419)$ were not significantly different from the control group, but NO levels in groups 2, 3, and 4 ( $P=0.012, P=0.018$, and $P=0.003$, respectively) were decreased compared with the control group (Figure 2a). Heart NO levels significantly decreased in groups 3 and 4 ( $P=0.002$ and $P<0.0001$, respectively) compared with the control group (Figure 2b). Kidney NO levels significantly decreased in groups 2,3 , and $4(P<0.0001$, $P<0.0001$, and $P<0.0001$, respectively) compared with the control group (Figure 2c). Liver NO levels significantly decreased in groups 2,3 , and $4(P=0.002$,

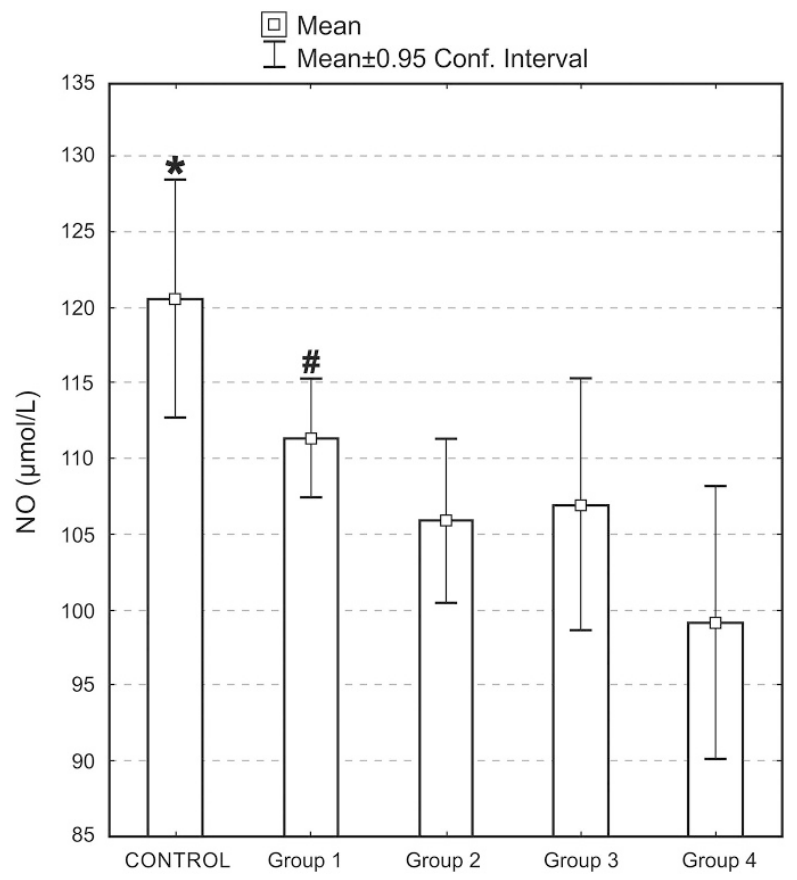

Figure 1 Effects of bevacizumab on the serum NO levels. ${ }^{*} P<0.05$ in control group compared with groups 2,3 , and 4 . Data are presented as mean \pm SD.

$P<0.0001$, and $P<0.0001$, respectively) compared with the control group (Figure 2d).

\section{Histological examination}

An examination of kidney sections with electron microscopy revealed no histopathological change in any of the groups (Figure 3).

\section{Discussion}

Experimental and clinical studies suggested that bevacizumab can pass through from the eye into systemic circulation and decrease VEGF levels after intravitreal injection. ${ }^{17,18}$ VEGF acts via VEGFR2, promoting NO synthase expression and NO activity. ${ }^{16}$ Previous studies have reported that VEGF-exposed human endothelial cells release NO. ${ }^{15}$ To the best of our knowledge, the effects of intravitreal bevacizumab on systemic levels of NO have not been previously investigated. For this reason, this study aimed to determine the possible effects of single-dose intravitreal bevacizumab on NO levels in serum and remote organs and to elucidate one of the possible mechanisms in the pathophysiology of hypertension.

In this study, serum, liver, and kidney NO levels significantly decreased a week after intravitreal injection of bevacizumab. Intravitreal bevacizumab significantly decreased serum VEGF levels 2 and 4 weeks after 
a

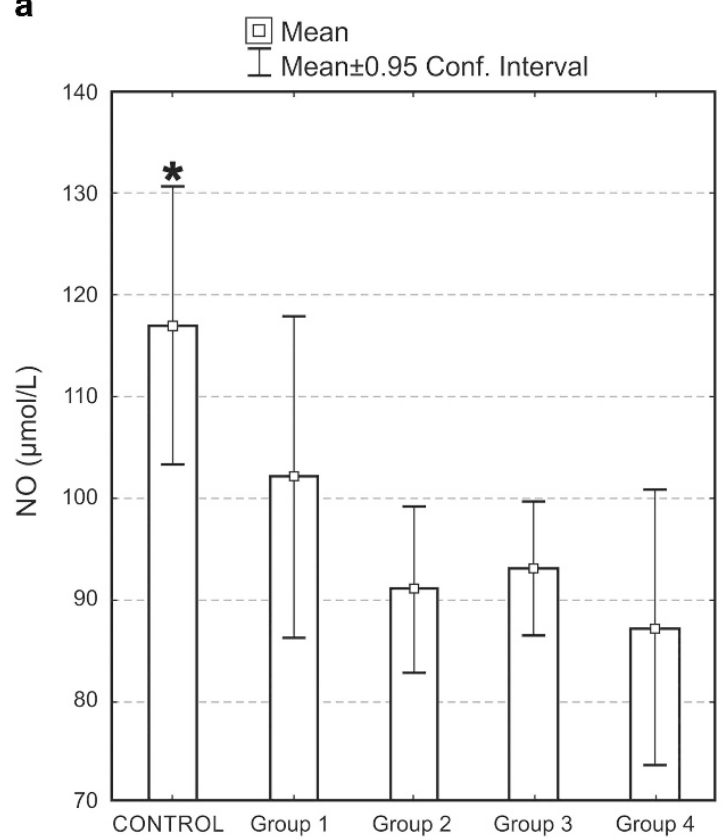

C

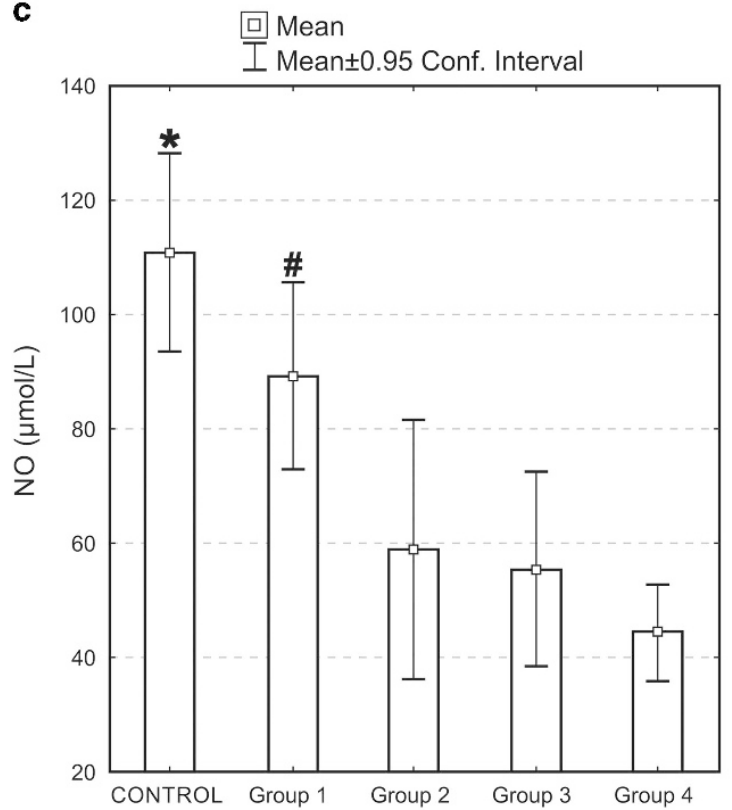

b

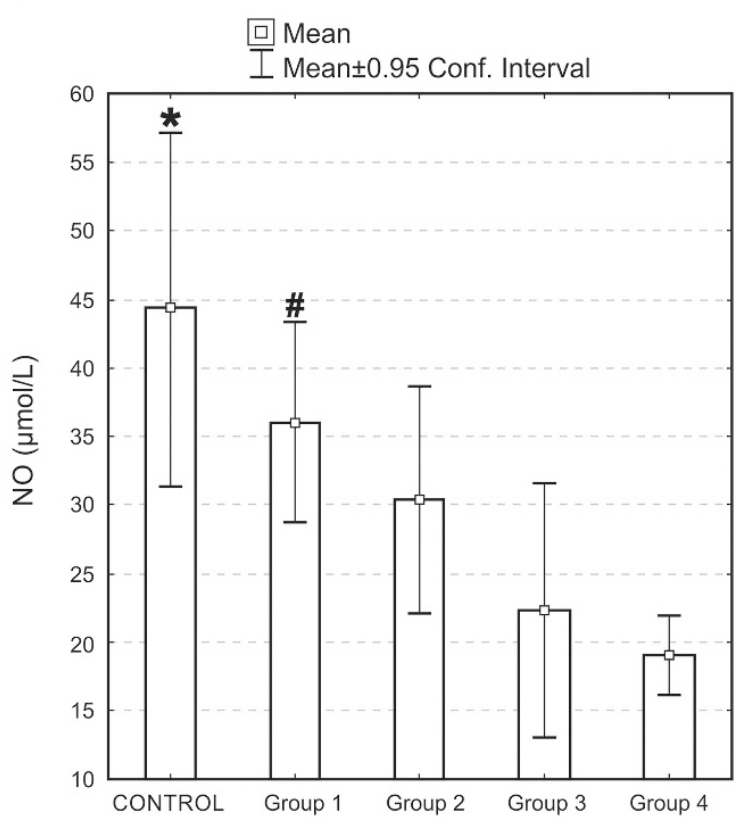

d

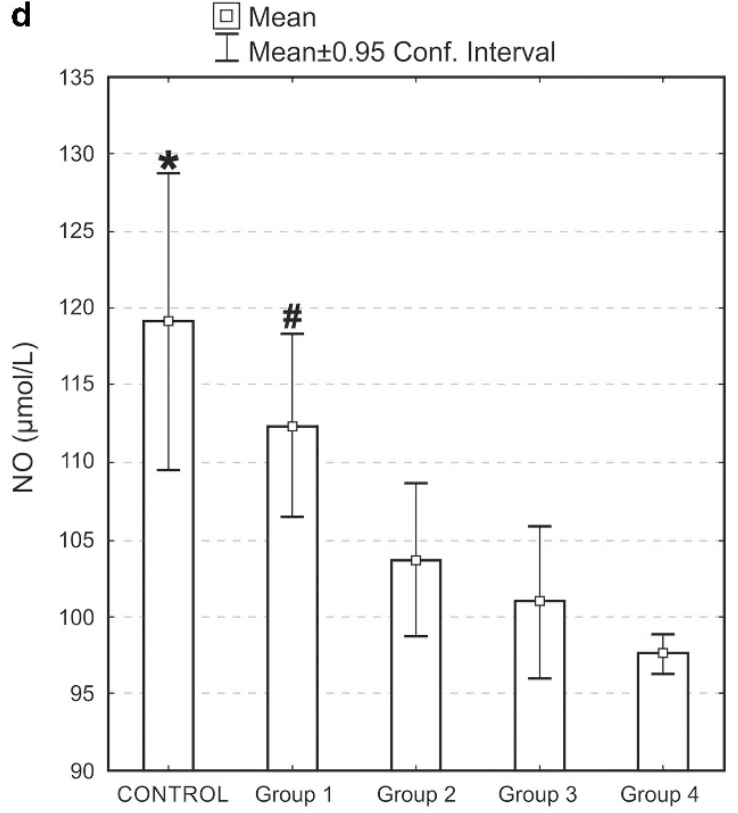

Figure 2 Effects of bevacizumab. (a) Brain NO levels. ${ }^{*} P<0.05$ in control group compared with groups 2, 3, and 4. (b) Heart NO levels. ${ }^{*} P<0.05$ in control group compared with groups 3 and $4 .{ }^{*} P<0.05$ in group 1 compared with group 4 . (c) Kidney NO levels. ${ }^{*} P<0.001$ in control group compared with groups 2,3 , and $4 .{ }^{\#} P<0.05$ in group 1 compared with groups 3 and 4 . (d) Liver NO levels. ${ }^{*} P<0.05$ in the control group compared with groups 2,3 , and $4 .{ }^{*} P<0.05$ in group 1 compared with groups 3 and 4 . All data are presented as mean $\pm \mathrm{SD}$.

intravitreal injection. Furthermore, liver VEGF levels significantly decreased 2 weeks after intravitreal injection. Kidney VEGF levels decreased in the study groups compared with the control group, but the change was not significant. ${ }^{19}$ This finding demonstrates that serum, liver, and kidney NO levels can be suppressed with intravitreal bevacizumab by binding to VEGF. Facemire $e a^{16}$ reported that the administration of a specific antibody for the major VEGF receptor, VEGFR2, to normal mice caused significant reductions in the expression of endothelial and neuronal NO synthases in the kidney. This effect on NO synthases is consistent with 


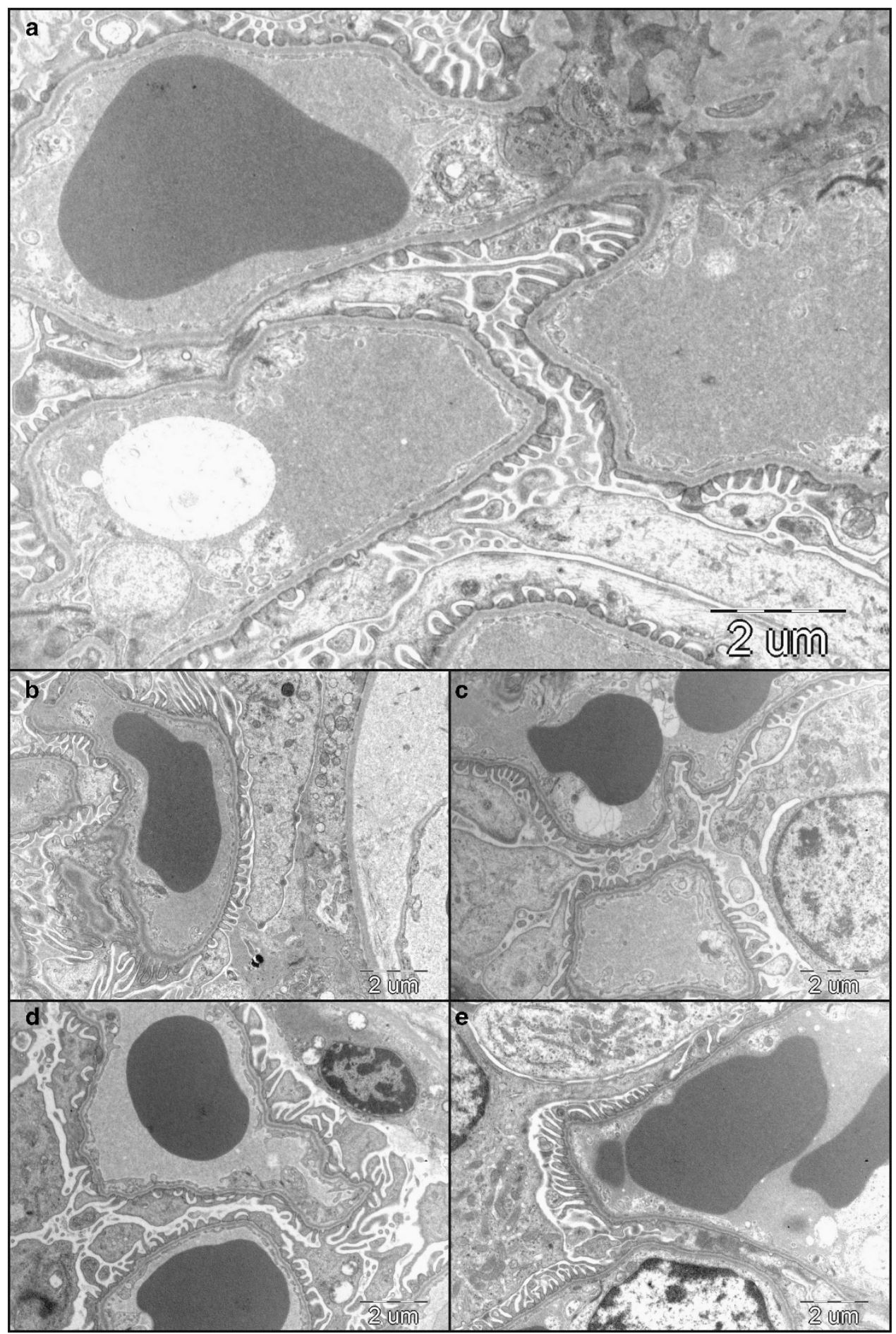

Figure 3 Electron microscopic evaluation of kidney tissues. (a) Control, (b) group 1, (c) group 2, (d) group 3, and (e) group 4.

the findings from previous studies that reported that human endothelial cells exposed to VEGF cause release of NO and upregulate both endothelial NO synthase mRNA and protein levels in a dose-dependent manner. ${ }^{15,20,21}$ Hypertension is the most common adverse effect of VEGF inhibitors and this increase in blood pressure is not clear. Suppression of serum NO levels by bevacizumab may be one mechanism underlying hypertension caused by VEGF inhibitors, and suggest that reducing NO production may be one of the mechanisms underlying hypertension caused by antiangiogenic agents targeting VEGF. Suppression of serum 
NO levels can cause reduction of renal perfusion and this condition can be stimulated by renin-angiotensinaldosterone (RAA) system. ${ }^{16}$ Stimulation of the RAA system causes water-sodium retention and results in increased blood pressure. One of the side effects of systemic bevacizumab therapy includes proteinuria, an important indicator of renal toxicity. Glomerular filtration barrier is formed by podocytes, basement membrane, and capillary endothelial cells. Defects in this barrier lead to proteinuria. VEGF is likely to be an essential molecule for kidney development, and especially for glomerulogenesis and nephrogenesis. ${ }^{22,23}$ Furthermore, it has been demonstrated that autocrine VEGF secretion is important for podocyte survival. ${ }^{24}$ Therefore, it has been supposed that inhibition of VEGF may cause podocyte injury and consequent loss of podocytes or failure of podocyte function that may further lead to the development of proteinuria. However, to our knowledge, the renal effects of intravitreal bevacizumab have not been evaluated at the microscopic level. In this study, electron microscopic data did not show any of the pathological changes in glomerular filtration barrier after injection of a single dose of bevacizumab. However, the renal effects of repeated intravitreal bevacizumab administration would require investigation.

$\mathrm{NO}$ is known to protect against apoptosis in some cell types, including hepatocytes; therefore, the growth regulatory actions of $\mathrm{NO}$ may be particularly relevant in liver regeneration. Furthermore, NO is synthesized by liver parenchymal and nonparenchymal cells from arginine. ${ }^{25} \mathrm{NO}$ induced programmed cell death during the early stages of rat liver regeneration. ${ }^{25}$ In this study, the suppression of liver NO production by bevacizumab may have been prevented by VEGF induction, which may have resulted in the inhibition of revascularization of the regenerating liver.

Brain NO levels significantly decreased 1 week after intravitreal injection of bevacizumab. VEGF concentrations in the brain decreased in the study groups, but no significant differences were found between them. We also demonstrated that intravitreal bevacizumab injections passed the blood-brain barrier and reached the brain parenchyma. ${ }^{19}$ Studies have shown that VEGF mRNA is expressed in normal brain tissue. ${ }^{26}$ Moreover, Mayhan ${ }^{27}$ reported that an infusion of VEGF increases NO synthesis in rat brains. In light of these findings, it is suggested that intravitreal bevacizumab-mediated VEGF inhibition can affect the expression of NO synthases in brain that may further lead to a decrease in NO levels. Furthermore, Artunay et $a l^{28}$ reported that the use of intravitreal bevacizumab may induce reversible posterior leukoencephalopathy (RPL). Bevacizumab may cause cerebral vasospasm via suppression of NO and can induce RPL.
In this study, heart NO levels significantly decreased 14 and 28 days after intravitreal injection of bevacizumab. However, there was no significant change of heart VEGF concentration in the study groups. ${ }^{19}$ Matsunaga et $a^{29}$ demonstrated that $\mathrm{NO}$ is an important regulator of coronary collateral growth, and the expression of VEGF is induced by ischemia. Suppression of NO by bevacizumab may inhibit coronary collateral growth and healing in heart.

In conclusion, this study showed that a single dose of intravitreal bevacizumab decreased NO levels in serum, brain, heart, liver, and kidneys. Decrease of NO level may explain hypertension as an adverse effect of bevacizumab. Furthermore, decreased NO levels may inhibit angiogenesis and healing in these organs. However, the main limitation of this study is that it was on rabbits and not humans. Therefore further studies are required to elucidate the effects of bevacizumab injections on serum NO concentrations and distant organs in humans.

\section{Summary}

What was known before

- The effect of intravitreal bevacizumab on nitric oxide level is unknown.

\section{What this study adds}

- Our study suggests that bevacizumab can affect nitric oxide levels in both serum and vital organs.

\section{Conflict of interest}

The authors declare no conflict of interest.

\section{Acknowledgements}

This study was supported by Mersin University Scientific Research Fund (Grant No: BAP-TF CTB (ED) 2011-3 TU).

\section{References}

1 Ferrara N. Vascular endothelial growth factor: basic science and clinical progress. Endocr Rev 2004; 25: 581-611.

2 Shibuya M, Yamaguchi S, Yamane M, Ikeda T, Tojo A, Matsushime $\mathrm{H}$ et al. Nucleotide sequence and expression of a novel human receptor-type tyrosine kinase gene (flt) closely related to the fms family. Oncogene 1990; 5: 519-524.

3 Terman BI, Dougher VM, Maglione D, Dimitrov D, Armellino DC, Gospodarowicz D et al. Identification of the KDR tyrosine kinase as a receptor for vascular endothelial cell growth factor. Biochem Biophys Res Commun 1992; 187: 1579-1586.

4 Warren RS, Yuan H, Matli MR, Gillett NA, Ferrara N. Regulation by vascular endothelial growth factor of human colon cancer tumorigenesis in a mouse model of 
experimental liver metastasis. J Clin Invest 1995; 95: 1789-1797.

5 Folkman J. Angiogenesis in cancer, vascular, rheumatoid and other disease. Nat Med 1995; 1: 27-31.

6 Ferrara N, Hillan KJ, Novotny W. Bevacizumab (Avastin), a humanized anti-VEGF monoclonal antibody for cancer therapy. Biochem Biophys Res Commun 2005; 333: 328-335.

7 Spaide RF, Laud K, Fine HF, Klancnik Jr, JM, Meyerle CB, Yannuzzi LA et al. Intravitreal bevacizumab treatment of choroidal neovascularization secondary to age related macular degeneration. Retina 2006; 26: 383-390.

8 Haritoglou C, Kook D, Neubauer A, Wolf A, Priglinger S, Strauss $\mathrm{R}$ et al. Intravitreal bevacizumab (Avastin) therapy for persistent diffuse diabetic macular edema. Retina 2006; 26: 999-1005.

9 Avery RL, Pearlman J, Pieramici DJ, Rabena MD, Castellarin AA, Nasir MA et al. Intravitreal bevacizumab (Avastin) in the treatment of proliferative diabetic retinopathy. Ophthalmology 2006; 113: 1695e1-e15.

10 Jaissle GB, Leitritz M, Gelisken F, Ziemssen F, Bartz-Schmidt KU, Szurman P. One-year results after intravitreal bevacizumab therapy for macular edema secondary to branch retinal vein occlusion. Graefes Arch Clin Exp Ophthalmol 2009; 247: 27-33.

11 Arias L, Planas N, Prades S, Caminal JM, Rubio M, Pujol O et al. Intravitreal bevacizumab (Avastin) for choroidal neovascularisation secondary to pathological myopia: 6-month results. Br J Ophthalmol 2008; 92: 1035-1039.

12 Michels S, Rosenfeld PJ, Puliafito CA, Marcus EN, Venkatraman AS. Systemic bevacizumab (Avastin) therapy for neovascular age-related macular degeneration twelveweek results of an uncontrolled open-label clinical study. Ophthalmology 2005; 112: 1035-1047.

13 Rich RM, Rosenfeld PJ, Puliafito CA, Dubovy SR, Davis JL, Flynn Jr, HW et al. Short-term safety and efficacy of intravitreal bevacizumab (avastin) for neovascular age related macular degeneration. Retina 2006; 26: 495-511.

14 Rasier R, Artunay O, Yuzbasioglu E, Sengul A, Bahcecioglu H. The effect of intravitreal bevacizumab (avastin) administration on systemic hypertension. Eye 2009; 23: 1714-1718.

15 Morbidelli L, Chang CH, Douglas JG, Granger HJ, Ledda F, Ziche M. Nitric oxide mediates mitogenic effect of VEGF on coronary venular endothelium. Am J Physiol 1996; 270: H411-H415.

16 Facemire CS, Nixon AB, Griffiths R, Hurwitz H, Coffman TM Vascular endothelial growth factor receptor 2 controls blood pressure by regulating nitric oxide synthase expression. Hypertension 2009; 54: 652-658.

17 Matsuyama K, Ogata N, Matsuoka M, Wada M, Takahashi K, Nishimura T. Plasma levels of vascular endothelial growth factor and pigment epithelium-derived factor before and after intravitreal injection of bevacizumab. Br J Ophthalmol 2010; 94: 1215-1218.

18 Bakri SJ, Snyder MR, Reid JM, Pulido JS, Singh RJ. Pharmacokinetics of intravitreal bevacizumab (Avastin). Ophthalmology 2007; 114: 855-859.

19 Dinc E, Yildirim O, Yilmaz N, Canacankatan N, Ayaz L, Ozcan $\mathrm{T}$ et al. Intravitreal bevacizumab effects on VEGF levels in distant organs: an experimental study. Cutan Ocul Toxicol 2014; 33: 275-282.

20 Hood JD, Meininger CJ, Ziche M, Granger HJ. VEGF upregulates ecNOS message, protein and NO production in human endothelial cells. Am J Physiol 1998; 274: H1054-H1058.

21 Wu HM, Huang Q, Yuan Y, Granger HJ. VEGF induces NO-dependent hyperpermeability in coronary venules. Am J Physiol 1996; 271: H2735-H2739.

22 Kitamoto Y, Tokunaga H, Tomita K. Vascular endothelial growth factor is an essential molecule for mouse kidney development: glomerulogenesis and nephrogenesis. J Clin Invest 1997; 99: 2351-2357.

23 Sugimoto H, Hamano Y, Charytan D, Cosgrove D, Kieran M, Sudhakar A et al. Neutralization of circulating vascular endothelial growth factor (VEGF) by anti-VEGF antibodies and soluble VEGF receptor 1 (sFlt-1) induces proteinuria. J Biol Chem 2003; 278: 12605-12608.

24 Müller-Deile J, Worthmann K, Saleem M, Tossidou I, Haller $\mathrm{H}$, Schiffer M. The balance of autocrine VEGF-A and VEGF-C determines podocyte survival. Am J Physiol Renal Physiol 2009; 297: F1656-F1667.

25 Ronco MT, Alvarez Mde L, Monti JA, Carrillo MC, Pisani GB, Lugano MC et al. Role of nitric oxide increase on induced programmed cell death during early stages of rat liver regeneration. Biochim Biophys Acta 2004; 1690: $70-76$.

26 Monacci WT, Merrill MJ, Oldfield EH. Expression of vascular permeability factor/vascular endothelial growth factor in normal rat tissues. Am J Physiol 1993; 264: C995-C1002.

27 Mayhan WG. VEGF increases permeability of the bloodbrain barrier via a nitric oxide synthase/cGMP dependent pathway. Am J Physiol 1996; 276: C1148-C1153.

28 Artunay O, Yuzbasioglu E, Rasier R, Sengul A, Bahcecioglu H. Posterior reversible encephalopathy after intravitreal bevacizumab injection in patient with choroidal neovascular membrane secondary to age-related maculopathy. J Ocul Pharmacol Ther 2010; 26: 301-303.

29 Matsunaga T, Warltier DC, Weihrauch DW, Moniz M, Tessmer J, Chilian WM. Ischemia-induced coronary collateral growth is dependent on vascular endothelial growth factor and nitric oxide. Circulation 2000; 102: 3098-3103. 